\title{
Combining Parameters of Fuel and Greenhouse Gas Costs as Single Objective Function for Optimization of Power Flow
}

\author{
Ignatius Riyadi Mardiyanto*1, Hermagasantos Zein ${ }^{2}$, Adi Soeprijanto ${ }^{3}$ \\ ${ }^{, 3}$ Sepuluh November Institute of Technology, Indonesia \\ ${ }_{1,2}$ Bandung State of Polytechnic, Indonesia \\ *Corresponding author, e-mail: Ig_R_M@yahoo.com', hermaga_s@yahoo.com² ${ }^{2}$, adisupits@gmail.com ${ }^{3}$
}

\begin{abstract}
The Kyoto Protocol is a protocol that highlights on greenhouse gases that have been adopted by many countries. Based on this protocol, power plants that produce emissions are encouraged to pay compensation. Conventionally, optimization of fuel mix in the electric power system components has not involved emission charges on the electricity system. This paper proposes a single objective function of a mathematical model for the calculation of power flow optimization involving greenhouse gas emissions costs to the fuel cost function. The single objective function derived using the mathematical model approach with linear heat rate function, in order to get the relationship between the fuel cost function with GHG emission. Namely, the function of energy costs as a combination of fuel costs and GHG emission costs can be shown as a quadratic function.
\end{abstract}

Keywords: heat rate, fuel cost, a GHG costs

Copyright $\odot 2017$ Universitas Ahmad Dahlan. All rights reserved.

\section{Introduction}

The study of energy and emissions management has been a lot written in the studies, but the objective function was discussed separately. Some examples of this can be traced in the books [1, 2] or in the papers [3-7]. Adoption of emissions regulations can be traced within the Kyoto Protocol. These Protocol primarily regulates greenhouse gas (GHG) emissions, i.e., as emissions gases from combustion results indicated to be the cause of global warming. In Indonesia, the Kyoto Protocol has been adopted with the name is the Clean Development Mechanism. In the electricity sector, power systems are expected to manage green energy in accordance with the provision [8]. The technique for managing green energy is to minimize emissions in electrical systems. One of the preconditions for the minimization of electrical systems is the selection of appropriate models to be used as an objective function [9].

According to Zhu [10], that the general problem OPF (Optimal Power Flow) is to obtain the optimal setting of a grid system. Namely, in a way that optimizes the objective function. The objective function can be the cost of power generation, grid losses, and emissions in power plants, load shedding, and also the limitations of the operating device. Furthermore, according to Soleman [9], the use of OPF with the objective function in the form of emission index is one of three strategies to reduce air emissions. The other two is a direct pollutant reduction strategies and strategies for the exchange of fuel with low-pollution fuel.

In this paper, will be merging two objective functions related to electric energy generation that is about the cost of power generation and GHG emissions due to combustion. This paper will conduct a formulation search to incorporate GHG emission as additional of the fuel parameters when used as an overall energy generation. That is to get a single objective function for an optimization of the power system that involves the costs of emissions and fuel.

In the combustion of fuel will be generated energy and exhaust emissions. The model of the fuel combustion system into this energy and flue gas can be reviewed as two objective functions. Namely the objective function of fuel and the objective function of combustion emissions. But in this paper, the two objective functions will be combined into a new purpose function that is the purpose of the combustion function. This new objective function will generate 
new function parameters, which consist of fuel function parameters and GHG emission function parameters.

In the description of this paper will be a search to get the parameters combined above. Namely by using the performance curve as the heat rate curve of the power plant. The search results on the fuel cost function of the heat rate have discussed in the papers, among others about the modeling cost curve [11,12]. But for the relationship of GHG emissions and fuel to heat rate is not writing clearly. In this paper, there will be a deterministic theoretical review of the relationship between heat rate and GHG emissions and fuel. So it will get important parameters related to the emissions, fuel and heat rate of a power generation.

This paper describes the parameters of a fuel cost function and GHG emission cost as a single function with the parameters depending on the component of the heat rate, fuel composition, fuel price, and GHG emission price. This is consistent with the search results of GHG emission paper i.e. by using a cost estimation approaches such as reference at [13]. The joining of parameters so that it becomes a deterministic objective function makes it easy to optimize the electrical system which involves the function of fuel cost and emission cost. Thus a method of deterministic classical optimization such as interior point [14], it can be done. In this paper, the simulation will be performed using the interior point method.

According to the Kyoto Protocol on GHG, the process of burning fossil fuels for electricity generation will bring $\mathrm{CO}_{2}$ emissions as a result of direct combustion, and the reaction of nitric oxide $(\mathrm{NO})$ to nitrous oxide $\left(\mathrm{N}_{2} \mathrm{O}\right)$ from the reaction of fuel in the combustion process as well as the reaction of combustion air at high temperatures, see [15-22]. Nitrous oxide is relatively stable at low temperatures so the $\mathrm{N}_{2} \mathrm{O}$ gas goes out from the stack also becomes a greenhouse gas, like $\mathrm{CO}_{2}$ gas. According to the Kyoto Protocol, $\mathrm{N}_{2} \mathrm{O}$ has emission factor equivalent to $310 \mathrm{CO}_{2}$ emissions. In addition, the combustion of fuel gas often remains unburned $\mathrm{CH}_{4}$ gas is vented to the atmosphere, according to the Kyoto Protocol also includes material GHG emissions [8]. This gas is usually very small in number, but have the potential $\mathrm{GHG}$ or $\mathrm{CO}_{2 \mathrm{e}}$ by 21 times that of $\mathrm{CO}_{2}$.

And then, in this study will be a mathematical formulation to obtain the objective function model, for the operating costs consist of the fuel cost and the GHG cost, with the condition of stoichiometry. GHG cost is primarily the cost of carbon dioxide equivalent $\left(\mathrm{CO}_{2 \mathrm{e}}\right)$ emissions. This objective function model is in the form of merging with the fuel costs and emissions costs in the operation of the electrical system, to obtain the sequence of unit de-commitment and the results of the calculation of the value of the optimization.

From a reference [22], it is known that a decrease heat rate results in reduced greenhouse gas emissions, due to GHG emissions depends on the amount of fuel burned at power plants. In this study, we will use the approach heat rate to as a base model of the electric energy generation cost function.

In this paper will try outlined that the model approach quadratic function to model of the cost function GHG emissions and fuel cost by using basic functions of linear heat rate, it is still good enough to use. Using a model approach quadratic function is presumably very easy to get the parameters of the model function. After getting the objective function can be performed simulation optimization in power system operation.

\section{Problem Formulation}

Combustion of fossil fuels in power plants, consisting of mainly three different combustion reactions $[15,23]$. The first is the combustion reaction between the carbon materials (C) to oxygen $\left(\mathrm{O}_{2}\right)$ into carbon dioxide $\left(\mathrm{CO}_{2}\right)$. The second is the reaction between nitrogen $(\mathrm{N})$ and oxygen $\left(\mathrm{O}_{2}\right)$ at temperatures above $800{ }^{\circ} \mathrm{C}$ to produce nitrogen oxides (NOx) are known as Fuel-NOx. In addition, for burning in power plants at high temperatures (above $1200{ }^{\circ} \mathrm{C}$ ), it also happens that the reaction of NOx formation known as Thermal-NOx. Most of the NO (part of NOx) reacts with $\mathrm{N}$ to become $\mathrm{N}_{2} \mathrm{O}$, and the others will remain as $\mathrm{NO}_{x}$. And the third is a reaction between sulfur $(\mathrm{S})$ contained in the fuel reacts with oxygen $\left(\mathrm{O}_{2}\right)$ to produce sulfur oxides (SOx).

Especially for GHG, based on the three types of combustion reactions over categorization and the results of the Kyoto Protocol [8], the GHG emission from thermal power plants, the main one is carbon dioxide $\left(\mathrm{CO}_{2}\right)$, and the other is a nitrous oxide $\left(\mathrm{N}_{2} \mathrm{O}\right)$. Sulfur oxides (SOx) is not categorized as GHG emission in this protocol. In the gas turbine power plant 
with a fossil fuel source in the form of a liquid or gas, unburning methane $\left(\mathrm{CH}_{4}\right)$ is also included as GHG emissions from power plants [24].

Nitrous Oxide is a part of the reaction $\mathrm{NO}+\mathrm{N}$ in the combustion process with high temperature. $\mathrm{N}_{2} \mathrm{O}$ can react with the chars $(\mathrm{C})$ will be decomposed into $\mathrm{N}_{2}$ and $\mathrm{CO}$ at a pressure $(0.2 \mathrm{MPa}$ to $1.0 \mathrm{MPa})$ [25] or temperature is relatively high $\left(>800{ }^{\circ} \mathrm{C}\right)$ [26]. It can be said that in an effort to decrease $\mathrm{NO}_{\mathrm{x}}$ by burning low temperature $\left(<900{ }^{\circ} \mathrm{C}\right)$ turned out to increase the levels of $\mathrm{N}_{2} \mathrm{O}$ emissions from power plants.

Here is the formulation of the proposed objective function as a function of energy cost model in power plant operations involving GHG emissions from power plants i.e. $\mathrm{CO}_{2}$ and $\mathrm{N}_{2} \mathrm{O}$, in accordance with the protocol on the environment. The definition of energy cost function here is a combination of fuel costs and emission costs due to the generation of electrical energy from the combustion process of fuel.

\subsection{Carbon Dioxide Costs}

In a simplified approach, tracing air emissions at power plants can be used as a book Fundamentals of Combustion Processes [27], or book [28]. That is to explore the process of conversion of fuel $(\mathrm{C})$ through the combustion process, it will be obtained carbon dioxide $\left(\mathrm{CO}_{2}\right)$ emissions and there will be a release of energy in a certain amount, or in another notation:

$$
\text { Fuel }(\mathrm{C})+\operatorname{Oxidizer}\left(\mathrm{O}_{2}\right) \rightarrow \text { Results combustion }\left(\mathrm{CO}_{2}\right)+\text { Energy }(\mathrm{kcal} / \mathrm{kg})
$$

On a result of combustion, in addition to the energy obtained to be converted into electricity, will also be obtained byproduct emissions $\left(\mathrm{CO}_{2}\right)$. These emissions to environmental issues will constitute the environmental costs, thereby generating emission can also be regarded as a direct result of the cost of electric energy generation using combustion process. In addition, thermal energy conversion process of combustion can be known with certainty that a number of greenhouse gases are a direct result of the amount of fuel burned. It can be said that for every 1 mole of carbon (C) if burned perfectly will produce 1 mole of $\mathrm{CO}_{2}$.

Cost of fuel is usually expressed in units of mass, then the unit mole of fuel (represented by the element carbon or $\mathrm{C}$ ) and $\mathrm{CO}_{2}$ gas combustion is then converted into mass units. As a result, it can be said that for every 1 ton of carbon contained in the fuel is burned perfectly will produce carbon dioxide emissions $\left(\mathrm{CO}_{2}\right)$ weighing $\frac{44}{12}$ ton. Furthermore, note also that the carbon content of the fuel depends on the type of fuel, the carbon content is usually written as a percentage of the total weight of the fuel. For example, every one ton of fuel then there is a $42 \%$ carbon element, it can be said that for every ton of fuel it burned will produce 3,667 tons $\times 42 \%$ or 1.4668 tons of carbon dioxide emissions $\left(\mathrm{CO}_{2}\right)$ or $\mathrm{GHG}$ emissions.

From the above, it has been shown that $\mathrm{CO}_{2}$ emissions are directly correlated to the amount of fuel. Because of this direct correlation, it can be calculated fuel costs and GHG emissions costs by using only one variable output of the electrical power.

Then note also that, the amount of fuel used in thermal power plant depends on the heat rate of the power plant and the energy supplied to the electrical system. Furthermore, the approach used in this calculation as a linear heat rate calculation the initial formulation. Verification of the model is done to show that the linear heat rate approach is relevant enough to be used as the basis of the cost function model. The advantage of using this linear approach is the obtainment of a quadratic function on the function of the cost of energy generation. Here are descriptions of the formulation.

\subsection{Nitrous Oxide Costs}

Pyrolysis and combustion at temperatures between $800{ }^{\circ} \mathrm{C}$ to $900{ }^{\circ} \mathrm{C}$, it is known that produce less of nitric oxide (NO) when compared to the higher combustion temperatures because of only Fuel-NOx dominant, but it produces nitrous oxide $\left(\mathrm{N}_{2} \mathrm{O}\right)$ is quite high. At the higher combustion temperatures turned out to be $\mathrm{N}_{2} \mathrm{O}$ that will react with the char $(\mathrm{C})$ so that the amount of $\mathrm{N}_{2} \mathrm{O}$ will decrease. Combustion under $900{ }^{\circ} \mathrm{C}$ cause Fuel-N converted into two gas emissions of the $\mathrm{N}_{2} \mathrm{O}$ and $\mathrm{NOx} . \mathrm{N}_{2} \mathrm{O}$ is quite high on the burning below $700{ }^{\circ} \mathrm{C}$ and decreases when the temperature has been rising. Instead NOx along with rising higher combustion temperatures. Combustion of Fuel- $\mathrm{N}$ at temperatures above $920{ }^{\circ} \mathrm{C}$ relatively stable at a certain value, which is about $8 \%$ Fuel- $\mathrm{N}$ converted to $\mathrm{N}_{2} \mathrm{O}$ and $\mathrm{NOx}$ by $80 \%$ [29]. 
The formation of nitrous oxide $\left(\mathrm{N}_{2} \mathrm{O}\right)$ from nitric oxide (NO) is approximately 1 to $3 \%$ of all $\mathrm{NO}_{x}$ resulting from the combustion process in the boiler type's fluidized bed (FBC) and will decline by about $0.1 \%$ in the combustion boiler type pulverizer (PC). Nitrous oxide $\left(\mathrm{N}_{2} \mathrm{O}\right)$ from the combustion process in power generation, in general, is between 20-200 ppm [30]. It relies on the combustion temperature and the type of boiler, for PC boiler about 20 ppm, and a CFB boiler $\mathrm{N}_{2} \mathrm{O}$ can reach 200 ppm.

Because the complexity of the formation of $\mathrm{N}_{2} \mathrm{O}$ from a combustion at power plants, the empirical approach is used in the formulation of this $\mathrm{N}_{2} \mathrm{O}$ emission calculation. This is consistent with the recommendations for the calculation of the Kyoto Protocol on emission factors. To that end, it is proposed that the formulation of empirical GHG on the type of $\mathrm{N}_{2} \mathrm{O}$ emissions is thus dependent on the type of boiler. For CFB boiler using a special emission factor CFB and PC using emission factors specific to the PC boiler.

\subsection{Formulation Model of GHG Emission and Fuel Costs}

At the thermal power plant, the process of conversion of fuel into electricity is measured using a scale conversion performance called heat rate. The amount of this conversion is based on the ability of plants to generate electricity. Heat rate can be simply expressed in a comparison between the amount of fuel calorific value is multiplied by the amount of fuel burned, and then it is divided by electrical energy generated or electrical energy produced $E_{\text {prod }}(k W h)$. In the formulation of the gross plant heat rate (GPHR) or $H R\left(\frac{k c a l}{k W h}\right)$ for fueled thermal power plant can be written as follows.

$$
H R=\frac{C V_{\text {fuel }} \times \text { Fuel }}{E_{\text {prod }}}
$$

with $C V_{\text {fuel }}\left(\frac{\mathrm{kcal}}{\mathrm{kg}}\right)$ is a calorific value of a fuel.

While this electrical energy according to the terms of the gross power generated $P_{T}(k W)$ is an electrical power generated multiplied by the time of generation $(h)$. According to this terms, in the mathematical equation can be regarded as,

$$
E_{\text {prod }}=P_{T} \times \text { time } .
$$

Using equations $/ I-1$ and $/ I-2$, it will further found the equation is

$$
Q_{\text {fuel }}=\frac{1}{C V_{\text {fuel }}} \times P_{T} \times H R
$$

With $P_{T}(k W)$ is a gross power generated by each unit of power plant to serve a power system. $Q_{\text {fuel }}\left(\frac{\mathrm{kg}}{\mathrm{h}}\right)$ is the rate of fuel consumption, usually written in units of mass per unit of time or $\frac{\text { Fuel }(\mathrm{kg})}{\text { time }(\mathrm{h})}$.

And then by using the equation of the rate of fuel consumption above, it can be stated that the rate of carbon emissions in the perfect combustion is equal to a constant multiplied by the percentage of carbon content in fuels $C_{f u e l}(\%)$, multiplied by the rate of fuel consumption. Under conditions of Stoichiometry, or the condition of the perfect combustion, the amount of the rate of carbon dioxide $Q_{\mathrm{CO}_{2}}\left(\frac{\mathrm{kg}}{\mathrm{h}}\right)$ on the rate of fuel can be written as follows.

$$
Q_{\mathrm{CO}_{2}}=\frac{44}{12} \times C_{\text {fuel }} \times Q_{\text {fuel }}
$$

With the global warming potential of $\mathrm{N}_{2} \mathrm{O}$ according to the Kyoto protocol amounted to 310. And, the fraction of nitrogen oxidized to nitrous oxides $\mathrm{N}_{2} \mathrm{O}$ or $\varepsilon_{N_{2} O}(\%)$ are depending on the heat of combustion of the boiler. Then, the amount of the rate of nitrous oxides $Q_{N_{2} O}\left(\frac{k g}{h}\right)$ can be calculated as follows.

$$
Q_{\mathrm{CO}_{2 e}\left(\mathrm{~N}_{2} \mathrm{O}\right)}=\frac{44}{14} \times \varepsilon_{\mathrm{N}_{2} \mathrm{O}} \times N_{\text {fuel }} \times 310 \times Q_{\text {fuel }}
$$


While the $\mathrm{CH}_{4}$ emission rate can be written as follows.

$$
Q_{\mathrm{CO}_{2 e}\left(\mathrm{CH}_{4}\right)}=\varepsilon_{\mathrm{CH}_{4}} \times \mathrm{CH}_{4(\mathrm{fuel})} \times 21 \times Q_{\text {fuel }}
$$

Thus in this paper, we propose a mathematical model formulation of fuel costs $\operatorname{Cost}_{E}\left(\frac{R p}{h}\right)$ on carbon-fueled power plants are as follows.

$\operatorname{Cost}_{E}=\left[\rho_{\text {fuel }}+\rho_{\text {em }} \times\left(\frac{44}{12} \times C_{\text {fuel }}+\frac{44}{14} \times \varepsilon_{N_{2} O} \times N_{\text {fuel }} \times 310+\varepsilon_{C_{4}} \times C H_{4(f u e l)} \times 21\right)\right] \times Q_{\text {fuel }}(7)$

In other forms, it can be written as follows.

$$
\operatorname{Cost}_{E}=K \times H R \times P_{T}
$$

With

$K$ is $\left[\rho_{\text {fuel }}+\rho_{\text {em }} \times\left(\frac{44}{12} \times C_{\text {fuel }}+\frac{44}{14} \times \varepsilon_{N_{2} O} \times N_{\text {fuel }} \times 310+\varepsilon_{C H_{4}} \times C H_{4(\text { fuel })} \times 21\right)\right] \times \frac{1}{C_{\text {fuel }}}$

With $\rho_{\text {fuel }}\left(\frac{R p}{k g}\right)$ is the price of fuel, and $\rho_{e m}\left(\frac{R p}{k g}\right)$ is the price of GHG (greenhouse gas) emissions equivalent which must be returned to the environment. Simplified without units, then the equation can be rewritten as follows. Heat rate $(H R)$ used above is a gross heat rate, due to be reviewed in the value of the total energy generated.

The total gross power generation $\left(P_{T}\right)$ is the amount of power used for its own purposes or auxiliary power $\left(P_{a u x}\right)$, and output power $(P)$ to supply power to the grid system. Then the total gross power generated can be written as follows.

$$
P_{T}=P_{\text {aux }}+P
$$

Auxiliary power $\left(P_{\text {aux }}\right)$ has a certain minimum value $\left(P_{\text {aux }(\min )}\right)$ which depends on the capacity and type of power plants. And auxilary power will be increase $\left(K_{0}\right)$ with increasing load demand $(P)$. Then, the auxiliary power can be written as follow.

$$
P_{\text {aux }}=P_{\text {aux }(\min )}+K_{0} \times P
$$

Using the equations $I I-9$ and $I I-10$, then the total power can be written as the following equation.

$$
P_{T}=P_{a u x(\min )}+K_{1} \times P
$$

with

$$
K_{1}=1+K_{0} \text { is a constant. }
$$

Heat rate will decrease if the load increases. Model of heat rate function may be a linear function, quadratic and polynomial equation of order three. In this simulation used heat rate equations approximated using a linear equation, that is because of maneuvering system services above $50 \%$ nominal power. This linear model is still relevant is used as shown in section III. 1 of this article.

To approach a linear function, it is known that the heat rate value depends on the electric power generated. The heat rate will be written as the following linear equation.

$$
H R=H R_{\text {nom }}+\left(K_{2} \times\left(P-P_{\text {min }}\right)\right)
$$

With $K_{2}$ is a gradient heat rate, as the following equation.

$$
K_{2}=\frac{H R_{\text {nom }}-H R_{\min }}{P_{\text {nom }}-P_{\min }}
$$


Heat rate at nominal load can be called as a nominal heat rate $\left(H R_{\text {nom }}\right)$. The minimum power $\left(P_{\min }\right)$ is defined as the minimum power can still be maintained by each unit to supply power to the grid. Using the equation of the electric power generated and the heat rate mentioned above, the fuel cost equation can then be written as follows.

$$
\operatorname{Cost}_{E}=K\left(K_{3}+K_{1} \times P\right) \times\left[H R^{\prime}{ }_{n o m}+\left(K_{2} \times P\right)\right]
$$

With

$$
K_{3} \text { is minimum of auxiliary power }\left(P_{\text {aux (min })}\right) \text {, and } H R^{\prime}{ }_{n o m}=H R_{\text {nom }}-K_{2} \times P_{\text {min }} \text {. }
$$

In another writing, the fuel cost equation can be rewritten as the following quadratic equation.

$$
\operatorname{Cost}_{E}=K \times H R^{\prime}{ }_{\text {nom }} \times\left[K_{3}+\left(\frac{K_{3} K_{2}}{H R^{\prime} \text { nom }}+K_{1}\right) \times P+\left(\frac{K_{1} K_{2}}{H R^{\prime} \text { nom }}\right) \times P^{2}\right]
$$

\subsection{Creating Power Plant Costs Model}

The electric energy generation costs, especially fuel costs and emissions costs in the short-term optimization approach can be approximated by the value of the power generated at each hour. Using these explanations, then the objective function can be determined more easily name the variable cost, which is the fuel costs that depend on plant performance or heat rate $(H R)$ consists of the cost of fuel thermal power plant or cost of raw of water for the raw material hydro power plant.

\subsubsection{Fuel Cost Model for Fired Thermal Power Plant}

Fuel cost function based on heat rate $\operatorname{Cost}_{f u e l}\left(\frac{R p}{h}\right)$, equation function is as follows.

$$
\operatorname{Cost}_{\text {fuel }}=\left(\rho_{\text {fuel }} \times \frac{H R_{\text {nom }}}{C V_{\text {fuel }}}\right) \times\left[K_{3}+\left(\frac{K_{3} K_{2}}{H R_{\text {nom }}}+K_{1}\right) \times P+\left(\frac{K_{1} K_{2}}{H R_{\text {nom }}}\right) \times P^{2}\right]
$$

\subsubsection{Cost model for Hydro Power Plant}

The energy cost function of hydro power plant Cost $_{H y d}$ is a function of variable costs due to levy water $(R p / h)$, namely:

$$
\operatorname{Cost}_{\text {Hyd }}=\rho_{\text {hyd }} \times \frac{1}{\tau \times g \times H} \times H R_{\text {hyd }} \times P_{T}
$$

with $\rho_{\text {hyd }}$ is the price of water levy set by the local government $\left(R p / m^{3}\right), H R_{h y d}$ is a function of the performance of hydro power plant in $\left(\right.$ tonne. $\left.\mathrm{m}^{2} / \mathrm{second}^{2} . \mathrm{kWh}\right), \tau$ is the density of water (tonne $\left./ \mathrm{m}^{3}\right), g$ is the gravitational constant $\left(\mathrm{m} / \mathrm{second}^{2}\right)$, and $H$ is the net head $(\mathrm{m})$.

\subsubsection{Objective Function Costs Model}

By manipulating the equations above, then the next generation cost function can be approached and written into the following quadratic equation.

$$
f(P)=\alpha+\beta \cdot P_{G}+\gamma \cdot P_{G}^{2}
$$

With $\alpha, \beta, \gamma$ are the parameters of the cost with a certain value which depends on the type of power plant, the parameters are as follows Table 1. 
Table 1. Fuel and Emission Cost Function Parameters

\begin{tabular}{|c|c|}
\hline Notation & Thermal Power Plant \\
\hline$\alpha$ & $=\left(\rho_{\text {hyd }} \times \frac{H R^{\prime}{ }_{\text {nom }}}{\tau \times g \times H}\right) K_{3}$, \\
\hline$\beta$ & $=\rho_{h y d} \times\left(\frac{K_{3} H R^{\prime}{ }_{n o m}+K_{1}}{\tau \times g \times H}\right)$ \\
\hline$\gamma$ & $=\rho_{h y d} \times\left(\frac{K_{1} K_{2}}{\tau \times g \times H}\right)$ \\
\hline$\delta$ & $=\left[\rho_{\text {fuel }}+\rho_{\text {em }} \times\left(\frac{44}{12} \times C_{\text {fuel }}+\frac{44}{14} \times \varepsilon_{N_{2} O} \times N_{\text {fuel }} \times 310+\varepsilon_{C_{4}} \times C H_{4(\text { fuel })} \times 21\right)\right] \times \frac{H R_{\text {nom }}^{\prime}}{C V_{\text {fuel }}}$ \\
\hline $\begin{array}{l}K_{1} \\
K_{2}\end{array}$ & $\begin{array}{c}=1+K_{0} \\
=\frac{H R_{\text {nom }}-H R_{\text {min }}}{P}-P\end{array}$ \\
\hline $\begin{array}{c}K_{3} \\
H R^{\prime}{ }_{n o m}\end{array}$ & $\begin{array}{c}=P_{\text {aux }(\min )} \\
=H R_{\text {nom }}+K_{-} 2 \times P \_ \text {min }\end{array}$ \\
\hline
\end{tabular}

\section{Verifying the Model}

Using the model of the objective function and constraint functions that have been outlined in advance, the next will be simulated.

\subsection{Verify Function of Heat Rate}

Heat generation rate will decrease if the load is increased, namely by following the curvature equation of order 2 [31]. Another view of the heat rate to changes in load can also be traced reference [32]. Using the reference, are shown in Table 2.

Table 2. Variations of Power Plant Heat Rate with Nominal Load 350 MW [32]

\begin{tabular}{cccccc}
\hline Load & $\mathrm{MW}$ & 350 & 300 & 200 & 100 \\
\hline Heat Consumption & $\mathrm{GJ} / \mathrm{h}$ & 2731.15 & 2366.70 & 1637.80 & 908.90 \\
Heat Rate & $\mathrm{kJ} / \mathrm{kWh}$ & 7803.3 & 7889.0 & 8189.0 & 9089.0 \\
Efficiency & $\%$ & 46.13 & 45.63 & 43.96 & 39.61 \\
\hline
\end{tabular}

Based on Table 2, the heat rate can be approached by a polynomial function. Using a three-order polynomial function, it has a regression approach with a coefficient of determination factor equal to 1. This function, shown in Figure 1 so which approach is best for heat rate function. Namely, it is the third order polynomial functions.

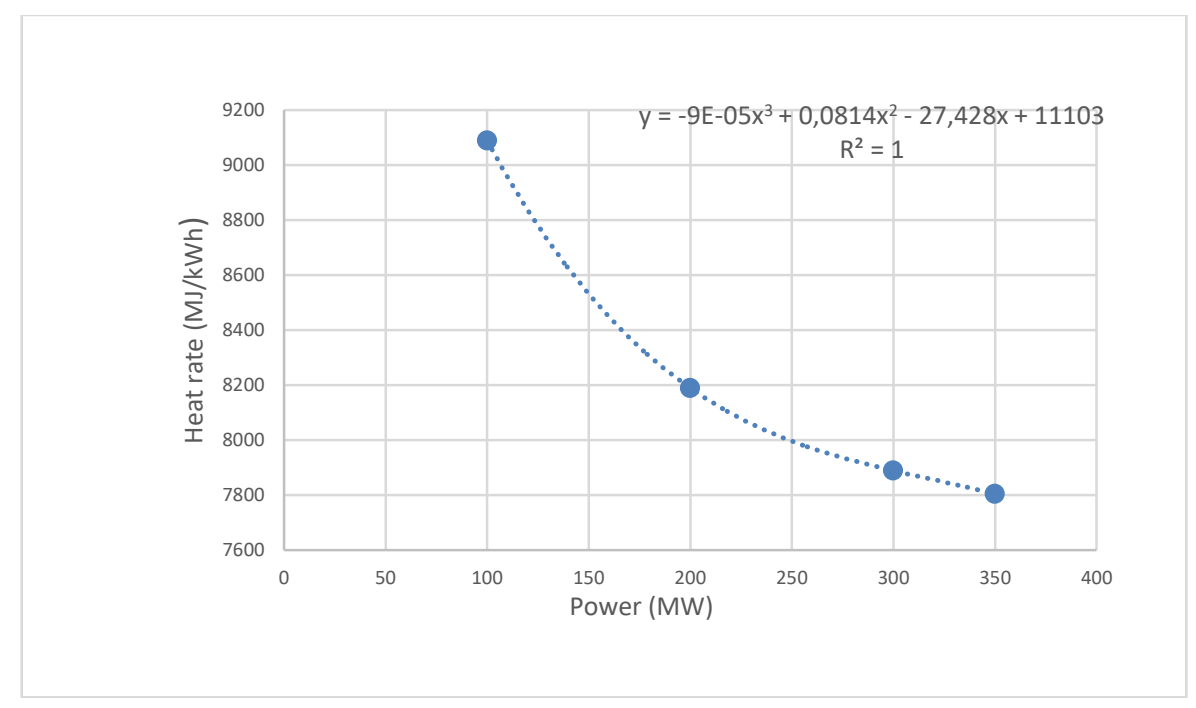

Figure 1. 3rd order function for the heat rate 
Interpretation of the data using a quadratic curve fitting it was shown as in Figure 2 below. In the image shown that by using a quadratic curve has a coefficient of determination 0.996. The coefficient of determination for this quadratic approach is included in the very good category.

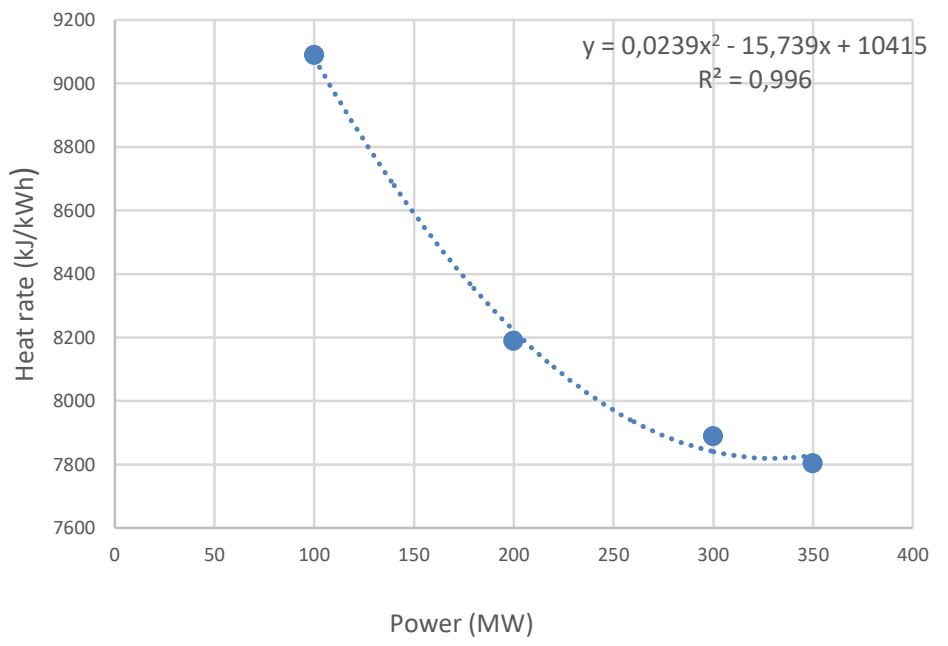

Figure0 2. Quadratic function of heat rate

Similarly, namely by using a linear curve fitting approach, which has a coefficient of a determination 0.9034 as seen in Figure 3 . With the determination coefficient value is more than $80 \%$, ie 0.9034 included in the category of a good approach.

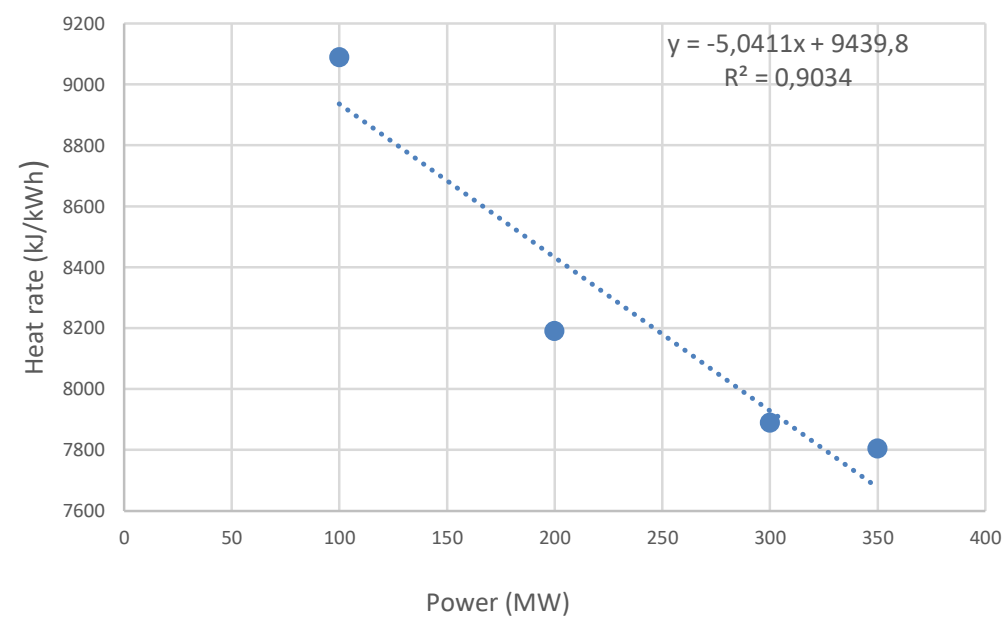

Figure 3. Linear function of heat rate

TELKOMNIKA Vol. 15, No. 4, December 2017: 1585-1600 
Thus, the linear approximation of changes in power plant heat rate was still relevant to the determination coefficient of regression is $90 \%$. The verification of the picture above, it can be said that the linear approximation of the function heat rate thermal power station is still relevant enough to be used as the basis for calculation. Other data, namely the use of linear heat rate can be traced to the paper as reference [33].

\subsection{Power Plant Data}

Based on Table 1 above, power plant data to obtain the cost equation can then be determined to consist of: nominal and minimum heat levels, fuel calorie values, carbon content, and nitrogen in fuel, and fuel prices and levels applicable greenhouse gas emissions in a region. To perform the calculation of cost model of the power plant, sample data to be used are follows. Auxiliary power for thermal power plant has a value between $8.5 \%$ and $11 \%$ of the electric power generated. For this simulation, the auxiliary power is assumed at $8.5 \%$ worth of the power generated by the power changes of $1 \%$ of the minimum power.

In this simulation, the Coal Power Plant (CCP) is assumed that all power plants using coal with calories around $5200 \mathrm{kcal} / \mathrm{kg}$, while the use of natural gas fuel gas with a methane content of around $95 \%$ Natural gas is used for the combined cycle power plant (CCPP) and gas turbine (GTPP). Coal price of $396 \mathrm{Rp} / \mathrm{kg}$, natural gas if converted to rupiah per kilogram is 2450 $\mathrm{Rp} / \mathrm{kg}$. While the price of GHG emissions is assumed around $36 \mathrm{Rp} / \mathrm{kg}$ as compensation for environmental costs [13]. Details of the data (dummy) Table 3 as follows.

Table 3. Power Plant Data (Dummy) as for the Determination of the Objective Function Parameters

\begin{tabular}{|c|c|c|c|c|c|c|c|c|c|c|c|c|c|}
\hline Bus & $\begin{array}{l}\text { Power } \\
\text { Plant }\end{array}$ & Pmin & Pnom & Qmin & $Q \max$ & Fuel price & $\begin{array}{l}\text { GHG } \\
\text { price }\end{array}$ & $\begin{array}{l}\mathrm{CV}_{\text {woll }} \\
\text { (HHV) }\end{array}$ & HRnom & HRmin & $\mathrm{C}_{\text {tual }}$ & $\mathrm{N}_{\text {tod }}$ & $\varepsilon_{N_{2} \mathrm{O}}$ \\
\hline & Thermal & $\mathrm{kW}$ & kW & kVAr & kVAr & $\mathrm{Rp} / \mathrm{kg}$ & $\mathrm{Rp} / \mathrm{kg}$ & $\mathrm{kcal} / \mathrm{kg}$ & $\mathrm{kcal} / \mathrm{kWh}$ & $\mathrm{Kcal} / \mathrm{kWh}$ & $\%$ & $\%$ & $\%$ \\
\hline 1 & CPP 1 & 346125 & 2769000 & -15 & 20 & 3 & 36 & $5330^{\circ}$ & 22 & 0 & 0.63 & 0.3 & 0.1 \\
\hline 8 & $\mathrm{CPP} 2$ & 178 & & & 1240000 & 39 & 36 & 5330 & 22 & 2408 & 0.63 & 0.3 & 0.1 \\
\hline 15 & CPP 3 & 165000 & 660000 & -60000 & 500000 & 396 & 36 & 5280 & 2433 & 2698 & 0.61 & 0.3 & 0.1 \\
\hline 17 & CCPP 1 & & & & 1260000 & 2450 & 38 & 12800 & 20 & 2278 & 0.73 & 0.2 & 0.1 \\
\hline 22 & CPP 4 & 31 & & & 192 & 39 & 36 & 5330 & 22 & 2 & 0.6 & 0 & 0.1 \\
\hline 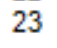 & GTPP 1 & 0 & 00 & -7 & 300000 & 2450 & 36 & 12800 & 2924 & 3268 & 0.73 & 0.2 & 0.1 \\
\hline & Hydro & & & & & $G\left(R p / m^{s}\right)$ & & $\mathrm{H}$ & 1/eff_nom & 1/eff_min & & & \\
\hline 10 & HPP 1 & 26250 & 700000 & -122000 & 500000 & 0.5 & & 52 & 2500 & 2640 & & & \\
\hline 11 & HPP 2 & 26250 & 700000 & -35000 & 440000 & 0.5 & & 40 & 2556 & 2643 & & & \\
\hline
\end{tabular}

\subsection{Results of Costs Function Model}

By using the dummy data as an example Table 3 then the next will be calculated parameter value of the cost function of the power plant. With estimates for the hydropower plant has a capacity factor of about 0.50 to 0.55 . Then, gas turbines have installed capacity factor of approximately 0.70 of annual operations. And then, the steam turbine has a capacity factor of 0.9 . Then the calculation results, using dummy data in the example above are shown as Table 4.

Table 4. The Results of Modeling Objective Function with and without GHG Costs

\begin{tabular}{rlccc}
\hline Bus & Power Plant & $\alpha$ & $\beta$ & $\gamma$ \\
\hline & \multicolumn{2}{l}{ Thermgl } \\
& (with GHG cost) & & & \\
1 & CPP 1 & 46.411 & 0.1974 & -0.0000226 \\
8 & CPP 2 & 24.502 & 0.2018 & -0.0000234 \\
15 & CPP 3 & 13.268 & 0.2118 & -0.0001134 \\
17 & CCPP 1 & 68.349 & 0.3543 & -0.0000575 \\
22 & CPP 4 & 54.059 & 0.2002 & -0.0000115 \\
23 & GTPP 1 & 20.834 & 0.5576 & -0.0005923 \\
& Hydro & & & \\
10 & HPP 1 & 0.588 & 0.0245 & -0.0000051 \\
11 & HPP 2 & 0.782 & 0.0325 & -0.0000042 \\
\hline
\end{tabular}

\begin{tabular}{|c|c|c|c|c|}
\hline Bus & PowerPlant & $\alpha$ & $\bar{\beta}$ & $\gamma$ \\
\hline & $\begin{array}{l}\text { Thermal (without } \\
\text { GHG cost) }\end{array}$ & & & \\
\hline $\begin{array}{l}1 \\
8\end{array}$ & $\begin{array}{l}\text { CPP } 1 \\
\text { CPP } 2\end{array}$ & $\begin{array}{l}38.356 \\
20.249\end{array}$ & $\begin{array}{l}0.1631 \\
0.1668\end{array}$ & $\begin{array}{l}-0.0000186 \\
-0.0000193\end{array}$ \\
\hline 15 & $\mathrm{CPP} 3$ & 11.026 & 0.1760 & -0.0000942 \\
\hline $\begin{array}{l}17 \\
22\end{array}$ & $\begin{array}{l}\text { CCPP } 1 \\
\text { CPP } 4\end{array}$ & $\begin{array}{l}65.771 \\
44.676\end{array}$ & $\begin{array}{l}0.3410 \\
0.1655\end{array}$ & $\begin{array}{l}-0.0000553 \\
-0.0000095\end{array}$ \\
\hline 23 & $\begin{array}{l}\text { GTPP } 1 \\
\text { Hydro }\end{array}$ & 20.049 & 0.5366 & -0.0005700 \\
\hline $\begin{array}{l}10 \\
11\end{array}$ & $\begin{array}{l}\operatorname{HPP} 1 \\
\operatorname{HPP} 2\end{array}$ & $\begin{array}{l}0.588 \\
0.782\end{array}$ & $\begin{array}{l}0.0245 \\
0.0325\end{array}$ & $\begin{array}{l}-0.0000051 \\
-0.0000042\end{array}$ \\
\hline
\end{tabular}


4. Model Simulation

\subsection{Equality Constraint in Power System}

Constraint equations for active power and reactive power are as follows [14].

a. Equations for active power at bus $i$ is,

$$
P_{G i}-P_{D i}-P_{L i}=0
$$

With the power of the load on the bus itself that is on the bus $i$ was $\left(P_{D i}\right)$, active power flow through the line from bus $\mathrm{i}$ to bus to $\mathrm{k}$ is $\left(P_{L i}\right)$, active power generated by the power plant is $\left(P_{G i}\right)$. The equation of the active power supplied by the bus $i$ to other bus is can be written as follows.

$$
P_{L i}=\sum_{k}^{N B}\left|V_{i}\right|\left|V_{k}\right|\left(G_{i k} \cos \theta_{i k}+B_{i k} \sin \theta_{i k}\right)
$$

With $\theta_{i k}=\theta_{i}-\theta_{k}$ is the difference between the phase angle $i$ to $k, G_{i k}$ is conductance of bus $i$ to bus $k, B_{i k}$ is suceptance from bus $i$ to bus $k$.

b. Equation of reactive power at bus $i$ is,

$$
Q_{L i}-Q_{G i}-Q_{B i}=0
$$

Furthermore, reactive power equations of bus $i$ to bus $k$ can be seen as a function of the following equation.

$$
Q_{L i}=\sum_{k}^{N B}\left|V_{i}\right|\left|V_{k}\right|\left(G_{i k} \sin \theta_{i k}-B_{i k} \cos \theta_{i k}\right)
$$

\subsection{Inequality Constraints}

Inequality constraints consist of inequality voltage, phase angle, active power and reactive power generation. Here is the inequality that is used [14].

a. inequality voltage and phase angle,

$$
\begin{aligned}
& V_{i}^{\text {min }} \leq V_{i} \leq V_{i}^{\text {max }} \\
& \theta_{i}^{\text {min }} \leq \theta_{i} \leq \theta_{i}^{\text {max }}
\end{aligned}
$$

b. active and reactive power inequalities,

$$
\begin{aligned}
& P_{G i}^{\text {min }} \leq P_{G i} \leq P_{G i}^{\text {max }}, \\
& Q_{G i}^{\text {min }} \leq Q_{G i} \leq Q_{G i}^{\max }
\end{aligned}
$$

\subsection{Grid Data and Electric Load Data}

To run a simulation of power flow optimization with an interior point method [14], the other data that would be required. The other data are a grid data and load data.

\subsubsection{Data Grid for the Simulation Model}

Data grids which include the data conductive electrical power, namely the from the bus $\left(f_{\text {bus }}\right)$ and bus ends $\left(t_{\text {bus }}\right)$ with a resistance, the admittance and the conductor ampacity (ampere capacity). Table 5 show example of a data grid that will be used as a simulation.

\subsubsection{Load Data for the Simulation Model}

Data for the electrical load is a load change in power at certain hours. Then the data is used to review the effect of the active power, and the amount of electrical power supplied to the grid as shown in Table 6. Active power $\left(P_{D}\right)$ unit is MW, and MVAR is for reactive power $\left(Q_{D}\right)$ unit. 
Table 5. Grid Data (Dummy) for Simulation

\begin{tabular}{|c|c|c|c|c|c|c|c|c|c|c|c|c|}
\hline$f_{\text {basi }}$ & $t_{\max }$ & $r$ & $\mathrm{x}$ & b & rateA & rateB & rateC & ratio & angle & status & $\begin{array}{l}\text { ang } \\
\text { min }\end{array}$ & $\begin{array}{l}\text { ang } \\
\max \end{array}$ \\
\hline 1 & 2 & 0.000626496 & 0.00700877 & 0 & 2500 & 2500 & 2500 & 0 & 0 & 1 & -360 & 360 \\
\hline 1 & 4 & 0.013133324 & 0.06257632 & 0.00599 & 2500 & 2500 & 2500 & 0 & 0 & 1 & -360 & 360 \\
\hline 2 & 5 & 0.146925792 & 0.00353057 & 0 & 2500 & 2500 & 2500 & 0 & 0 & 1 & -360 & 360 \\
\hline 3 & 4 & 0.001513179 & 0.01692831 & 0 & 2500 & 2500 & 2500 & 0 & 0 & 1 & -360 & 360 \\
\hline 4 & 5 & 0.001246422 & 0.01197501 & 0 & 2500 & 2500 & 2500 & 0 & 0 & 1 & -360 & 360 \\
\hline 4 & 18 & 0.000694176 & 0.0066693 & 0 & 2500 & 2500 & 2500 & 0 & 0 & 1 & -360 & 360 \\
\hline 5 & 7 & 0.00444188 & 0.0426754 & 0 & 2500 & 2500 & 2500 & 0 & 0 & 1 & -360 & 360 \\
\hline 5 & 8 & 0.0062116 & 0.059678 & 0 & 2500 & 2500 & 2500 & 0 & 0 & 1 & -360 & 360 \\
\hline 5 & 11 & 0.00411138 & 0.04599504 & 0.00442 & 2500 & 2500 & 2500 & 0 & 0 & 1 & -360 & 360 \\
\hline 6 & 7 & 0.001973648 & 0.01896184 & 0 & 2500 & 2500 & 2500 & 0 & 0 & 1 & -360 & 360 \\
\hline 6 & 8 & 0.0056256 & 0.054048 & 0 & 2500 & 2500 & 2500 & 0 & 0 & 1 & -360 & 360 \\
\hline 8 & 9 & 0.002822059 & 0.02711295 & 0 & 2500 & 2500 & 2500 & 0 & 0 & 1 & -360 & 360 \\
\hline 9 & 10 & 0.00273996 & 0.02632419 & 0 & 2500 & 2500 & 2500 & 0 & 0 & 1 & -360 & 360 \\
\hline 10 & 11 & 0.001474728 & 0.01416846 & 0 & 2500 & 2500 & 2500 & 0 & 0 & 1 & -360 & 360 \\
\hline 11 & 12 & 0.0019578 & 0.0219024 & 0 & 2500 & 2500 & 2500 & 0 & 0 & 1 & -360 & 360 \\
\hline 12 & 13 & 0.00699098 & 0.0671659 & 0.00643 & 2500 & 2500 & 2500 & 0 & 0 & 1 & -360 & 360 \\
\hline 13 & 14 & 0.013478 & 0.12949 & 0.01239 & 2500 & 2500 & 2500 & 0 & 0 & 1 & -360 & 360 \\
\hline 14 & 15 & 0.01353392 & 0.15140736 & 0.00364 & 2500 & 2500 & 2500 & 0 & 0 & 1 & -360 & 360 \\
\hline 14 & 16 & 0.01579856 & 0.1517848 & 0.00363 & 2500 & 2500 & 2500 & 0 & 0 & 1 & -360 & 360 \\
\hline 14 & 20 & 0.00903612 & 0.0868146 & 0 & 2500 & 2500 & 2500 & 0 & 0 & 1 & -360 & 360 \\
\hline 15 & 16 & 0.037539629 & 0.3606623 & 0.00863 & 2500 & 2500 & 2500 & 0 & 0 & 1 & -360 & 360 \\
\hline 16 & 17 & 0.00139468 & 0.0133994 & 0 & 2500 & 2500 & 2500 & 0 & 0 & 1 & -360 & 360 \\
\hline 16 & 23 & 0.003986382 & 0.04459666 & 0 & 2500 & 2500 & 2500 & 0 & 0 & 1 & -360 & 360 \\
\hline 18 & 19 & 0.014056 & 0.157248 & 0.01511 & 2500 & 2500 & 2500 & 0 & 0 & 1 & -360 & 360 \\
\hline 19 & 20 & 0.015311 & 0.171288 & 0.01646 & 2500 & 2500 & 2500 & 0 & 0 & 1 & -360 & 360 \\
\hline 20 & 21 & 0.010291 & 0.115128 & 0.01107 & 2500 & 2500 & 2500 & 0 & 0 & 1 & -360 & 360 \\
\hline 21 & 22 & 0.010291 & 0.115128 & 0.01107 & 0 & 2500 & 10 & 0 & 0 & 1 & 0 & 360 \\
\hline 22 & 23 & 0.004435823 & 0.04962466 & 0.00477 & 2500 & 2500 & 2500 & 0 & 0 & 1 & -360 & 360 \\
\hline
\end{tabular}

Table 6. Electric Load Data (Dummy)

\begin{tabular}{|c|c|c|c|c|c|c|c|c|c|c|c|c|c|c|}
\hline \multirow{2}{*}{\multicolumn{2}{|c|}{$\begin{array}{l}\text { Zone } \\
\text { Hour to }\end{array}$}} & \multirow{2}{*}{\multicolumn{2}{|c|}{$\begin{array}{l}1 \\
1\end{array}$}} & \multirow{2}{*}{\multicolumn{2}{|c|}{$\begin{array}{c}\text { Base kV } \\
2\end{array}$}} & \multirow{2}{*}{\multicolumn{2}{|c|}{$\begin{array}{c}500 \\
3\end{array}$}} & \multirow{2}{*}{\multicolumn{2}{|c|}{4}} & \multirow{2}{*}{\multicolumn{2}{|c|}{5}} & \multirow{3}{*}{ area } & \multirow{3}{*}{ Vmax } & \multirow{3}{*}{ Vmin } \\
\hline & & & & & & & & & & & & & & \\
\hline bus_i & type & $P_{D}$ & $\mathrm{Q}_{\mathrm{D}}$ & $P_{D}$ & $Q_{D}$ & $P_{D}$ & $\mathrm{Q}_{\mathrm{D}}$ & $P_{D}$ & $Q_{D}$ & $P_{D}$ & $Q_{D}$ & & & \\
\hline 1 & 3 & 353 & 125 & 553 & 250 & 353 & 45 & 353 & 75 & 553 & 175 & 1 & 1.1 & 0.9 \\
\hline 2 & 1 & 245 & 134 & 300 & 227 & 300 & 227 & 3 & 227 & 3 & 227 & 1 & 1.1 & 0.9 \\
\hline 3 & 1 & 260 & 31 & 360 & 31 & 660 & 161 & 660 & 161 & 660 & 161 & 1 & 1.1 & 0.9 \\
\hline 4 & 1 & 144 & 41 & 344 & 141 & 544 & 181 & 644 & 181 & 644 & 181 & 1 & 1.1 & 0.9 \\
\hline 5 & 1 & 397 & 115 & 597 & 45 & 697 & 215 & 697 & 215 & 697 & 215 & 1 & 1.1 & 0.9 \\
\hline 6 & 1 & 460 & 181 & 320 & 134 & 760 & 181 & 760 & 181 & 760 & 181 & 2 & 1.1 & 0.9 \\
\hline 7 & 1 & 546 & 241 & 346 & 141 & 646 & 170 & 646 & 170 & 646 & 170 & 2 & 1.1 & 0.9 \\
\hline 8 & 1 & 0 & 0 & 0 & 0 & 0 & 0 & 0 & 0 & 0 & 0 & 2 & 1.1 & 0.9 \\
\hline 9 & 1 & 423 & 217 & 323 & 117 & 823 & 317 & 823 & 317 & 823 & 317 & 2 & 1.1 & 0.9 \\
\hline 10 & 1 & 0 & 0 & 0 & 0 & 0 & 0 & 0 & 0 & 0 & 0 & 2 & 1.1 & 0.9 \\
\hline 11 & 1 & 0 & 0 & 0 & 0 & 0 & 0 & 0 & 0 & 0 & 0 & 2 & 1.1 & 0.9 \\
\hline 12 & 1 & 490 & 151 & 400 & 231 & 590 & 351 & 590 & 351 & 590 & 351 & 2 & 1.1 & 0.9 \\
\hline 13 & 1 & 397 & 186 & 247 & 146 & 397 & 136 & 597 & 186 & 597 & 186 & 2 & 1.1 & 0.9 \\
\hline 14 & 1 & 129 & 173 & 229 & 173 & 329 & 363 & 529 & 363 & 629 & 363 & 3 & 1.1 & 0.9 \\
\hline 15 & 1 & 0 & 0 & 0 & 0 & 0 & 0 & 0 & 0 & 0 & 0 & 3 & 1.1 & 0.9 \\
\hline 16 & 1 & 362 & 247 & 422 & 82 & 862 & 317 & 862 & 317 & 862 & 317 & 4 & 1.1 & 0.9 \\
\hline 17 & 1 & 310 & 141 & 310 & 91 & 410 & 91 & 410 & 113 & 510 & 113 & 4 & 1.1 & 0.9 \\
\hline 18 & 1 & 310 & 110 & 410 & 110 & 150 & 20 & 350 & 50 & 550 & 250 & 3 & 1.1 & 0.9 \\
\hline 19 & 1 & 377 & 117 & 220 & 110 & 277 & 17 & 477 & 137 & 477 & 137 & 3 & 1.1 & 0.9 \\
\hline 20 & 1 & 224 & 144 & 424 & 144 & 524 & 244 & 524 & 244 & 524 & 244 & 3 & 1.1 & 0.9 \\
\hline 21 & 1 & 258 & 196 & 220 & 96 & 358 & 206 & 458 & 206 & 458 & 206 & 4 & 1.1 & 0.9 \\
\hline 22 & 1 & 139 & 152 & 439 & 152 & 839 & 272 & 839 & 272 & 839 & 272 & 4 & 1.1 & 0.9 \\
\hline 23 & 1 & 313 & 25 & 130 & 0 & 13 & 0 & 13 & 0 & 67 & 0 & 4 & 1.1 & 0.9 \\
\hline
\end{tabular}

\subsubsection{Additional Data for the Simulation}

It is assumed that the data were taken during the dry season with a limited water supply. Due to the limited supply of water, it is known that the condition of hours to 1 to 3 hours to note that the Hydro Power Plant (HPP) is not enabled. PP-1 and HPP 2, they cannot serve the grid system. At that hour are ready for operation is the thermal power plant. In the hours to 4 to 5 , hydro power plants will be ready to serve the load on the grid system.

\subsection{Simulation Result}

Use the Interior point method for simulation optimization of energy costs, which consist of the cost of fuel and the cost of GHG emissions, the results can be shown in the following 
Table 7. As for running the program with no price of greenhouse gas emissions or no GHG cost, the value is zero. Then the results of running the program are as shown in Table 8.

Table 7. Summary Results of Running (with GHG Emissions Cost)

\begin{tabular}{|c|c|c|c|c|c|c|c|c|c|c|c|c|}
\hline \multicolumn{3}{|c|}{ Hour to } & \multicolumn{2}{|c|}{1} & \multicolumn{2}{|c|}{2} & \multicolumn{2}{|c|}{3} & \multicolumn{2}{|c|}{4} & \multicolumn{2}{|c|}{5} \\
\hline Bus & $\begin{array}{l}\text { Power } \\
\text { Plant }\end{array}$ & MW & MW & MVAr & $M W$ & MVAr & MW & MVAr & MW & MVAr & MW & MVAr \\
\hline $\begin{array}{l}1 \\
8\end{array}$ & $\begin{array}{l}\text { CPP } 1 \\
\text { CPP } 2\end{array}$ & $\begin{array}{l}2769 \\
1430\end{array}$ & $\begin{array}{l}2769.00 \\
1430.00\end{array}$ & $\begin{array}{l}269.42 \\
814.11\end{array}$ & $\begin{array}{l}2769.00 \\
1430.00\end{array}$ & $\begin{array}{l}496.54 \\
59950\end{array}$ & $\begin{array}{l}2769.00 \\
1430.00\end{array}$ & $\begin{array}{r}323.79 \\
119483\end{array}$ & $\begin{array}{l}2769.00 \\
1430.00\end{array}$ & $\begin{array}{l}344.51 \\
61278\end{array}$ & $\begin{array}{l}2769.00 \\
1430.00\end{array}$ & $\begin{array}{l}482.95 \\
72115\end{array}$ \\
\hline 10 & $\mathrm{HPP} 1$ & 700 & 0 & 0 & 0 & 0 & 0 & 0 & 700.00 & 295.95 & 700.00 & 373.26 \\
\hline 11 & HPP 2 & 700 & 0 & 0 & 0 & 0 & 0 & 0 & 700.00 & 455.65 & 700.00 & 461.22 \\
\hline 15 & $\mathrm{CPP} 3$ & 660 & 660.00 & 35.91 & 660.00 & -13.79 & 660.00 & 123.31 & 660.00 & 97.60 & 660.00 & 102.88 \\
\hline 17 & CCPP 1 & 1839 & 0 & 0 & 0 & 0 & 1223.64 & 346.04 & 815.23 & 348.39 & 1182.23 & 310.18 \\
\hline 22 & CPP 4 & 3180 & 851.31 & 123.94 & 1305.14 & 48.28 & 3180.00 & 300.98 & 3180.00 & 406.12 & 3180.00 & 348.24 \\
\hline 23 & GTPP 1 & 440 & 440.00 & 277.79 & 440.00 & 76.65 & 290.53 & 99.66 & 0 & 0 & 286.51 & 116.59 \\
\hline & Load & & 6137.00 & 2727.00 & 6594.00 & 2421.00 & 9532.0 & 3514.0 & 10235.0 & 3766.0 & 10889.00 & 4066.00 \\
\hline Powe & rgenergted & & 6150.31 & 1521.18 & 6604.14 & 1207.18 & 9553.16 & 2388.62 & 10254.23 & 2602.95 & 10907.74 & 2917.25 \\
\hline Bran & $\begin{array}{l}\text { h charging } \\
\text { (ini) }\end{array}$ & & & 1239.8 & & 1242.7 & & 1245.2 & & 1241.0 & & 1243.3 \\
\hline Obj & function & M.Rp/h & & 1156.50 & & 1236.06 & & 1911.48 & & 1712.69 & & 1932.55 \\
\hline Co & nverged & second & & 18.67 & & 6.91 & & 10.93 & & 14.33 & & 11.96 \\
\hline
\end{tabular}

Using Table 7 and Table 8 , it can be created percentage issuance costs against the cost of energy. To find out the effect of GHG emissions price on energy costs that have been optimized, are shown in the following Table 9.

Table 8. Summary Results of Running (without GHG Emissions Cost)

\begin{tabular}{|c|c|c|c|c|c|c|c|c|c|c|c|c|}
\hline \multicolumn{3}{|c|}{ Hour to } & \multicolumn{2}{|c|}{1} & \multicolumn{2}{|c|}{2} & \multicolumn{2}{|c|}{3} & \multicolumn{2}{|c|}{4} & \multicolumn{2}{|c|}{5} \\
\hline Bus & $\begin{array}{l}\text { Power } \\
\text { Plant }\end{array}$ & MW & MW & MVAr & MW & MVAr & MW & MVAr & MW & MVAr & MW & MVAr \\
\hline 1 & CPP 1 & 2769 & 2769.00 & 269.43 & 2769.00 & 496.54 & 2769.00 & 325.52 & 2769.00 & 349.04 & 2769.00 & 482.96 \\
\hline 8 & $\mathrm{CPP} 2$ & 1430 & 1430.00 & 814.12 & 1430.00 & 599.51 & 1430.00 & 1192.77 & 1430.00 & 629.55 & 1430.00 & 721.02 \\
\hline 10 & HPP 1 & 700 & 0 & 0 & 0 & 0 & 0 & 0 & 700.00 & 328.53 & 700.00 & 373.21 \\
\hline 11 & HPP 2 & 700 & 0 & 0 & 0 & 0 & 0 & 0 & 700.00 & 454.90 & 700.00 & 461.49 \\
\hline 15 & $\mathrm{CPP} 3$ & 660 & 660.00 & 35.92 & 660.00 & -13.79 & 660.00 & 125.19 & 660.00 & 100.72 & 660.00 & 103.61 \\
\hline 17 & CCPP 1 & 1839 & 0 & 0 & 0 & 0 & 1223.64 & 340.22 & 815.23 & 327.25 & 1182.23 & 310.41 \\
\hline 22 & CPP 4 & 3180 & 851.31 & 123.97 & 1305.14 & 48.28 & 3180.00 & 300.43 & 3180.00 & 413.33 & 3180.00 & 348.18 \\
\hline 23 & GTPP 1 & 440 & 440.00 & 277.75 & 440.00 & 76.64 & 290.53 & 104.49 & 0 & 0 & 286.51 & 116.36 \\
\hline & Logd & & 6137 & 2727 & 6594 & 2421 & 9532 & 3514 & 10235 & 3766 & 10889 & 4066 \\
\hline & Power & & 6150.31 & 1521.18 & 6604.14 & 1207.18 & 9553.16 & 2388.63 & 10254.22 & 2603.33 & 10907.74 & 2917.24 \\
\hline & Generated & & & & & & & & & & & \\
\hline & $\begin{array}{l}\text { Branch } \\
\text { arging (inj) }\end{array}$ & & & 1239.8 & & 1242.7 & & 1245.2 & & 1240.6 & & 1243.3 \\
\hline & j. function & M Rp/h & & 976.83 & & 1042.58 & & 1654.72 & & 1464.59 & & 1676.16 \\
\hline & onverged & second & & 10.34 & & 4.81 & & 8.52 & & 11.38 & & 10.27 \\
\hline
\end{tabular}

Table 9. Estimated Percentage of the Cost of Emissions to the Cost of Fuel in the Power System that has been Optimized

\begin{tabular}{|c|c|c|c|c|c|c|c|c|c|c|c|}
\hline & Hour to & 1 & & 2 & & 3 & & 4 & & 5 & \\
\hline & Unit & $M W$ & MVAr & $M W$ & MVAr & $M W$ & MVAr & MW & MVAr & $M W$ & MVAr \\
\hline Load & $\mathrm{MW}$ & 6137 & 2727 & 6594 & 2421 & 9532 & 3514 & 10235 & 3766 & 10889 & 4066 \\
\hline $\begin{array}{l}\text { Fuel with Emission Cost } \\
\text { (Energy Cost) }\end{array}$ & M Rp/h & & 1156.5 & & 1236.06 & & 1911.48 & & 1712.69 & & 1932.55 \\
\hline $\begin{array}{l}\text { Fuel without Emission } \\
\text { Cost }\end{array}$ & M Rp/h & & 976.83 & & 1042.58 & & 1654.72 & & 1464.59 & & 1676.16 \\
\hline $\begin{array}{l}\text { The results of emission } \\
\text { cost optimization }\end{array}$ & M Rp/h & & 179.67 & & 193.48 & & 256.76 & & 248.1 & & 256.39 \\
\hline $\begin{array}{l}\text { Comparis on of emission } \\
\text { costs onfuel costs }\end{array}$ & $\%$ & & $18 \%$ & & $19 \%$ & & $16 \%$ & & $17 \%$ & & $15 \%$ \\
\hline
\end{tabular}




\section{Analysis}

\subsection{Analysis of Modeling}

Formulation energy generation costs can be grouped into the costs of fuel and emission costs. Agreed GHG emission as a function of the cost is to use the Kyoto Protocol. By using these protocols, the cost of the main emissions at thermal power plants is the emission of $\mathrm{CO}_{2}$ and $\mathrm{N}_{2} \mathrm{O}$, as well as for gas-fired power plants are usually coupled with emissions of unburned $\mathrm{CH}_{4}$ gas. Of the three GHG gases are highly influential in the calculation of costs as a major component is $\mathrm{CO}_{2}$-emissions combustion. Furthermore, the incorporation of fuel costs and the costs of GHG emissions can be done using the single objective function of costs formulations as in Table 1.

The linear model of heat rate function selected for ease in providing data of power plant. Model function is a linear, it is also still has a good correlation with data from the reference search, i.e. the reference data on heat rate function of the load on the power plant. This is shown in Figure 3 namely, the model function of heat rate as a linear function has a coefficient of determination of regression at $90 \%$. The coefficient of determination above $80 \%$, can be said to have a very good correlation. The model can be used as a model for the calculation of heat rate changes on the power plant. The approach to this linear function will facilitate the calculation of the cost of fuel and emission costs.

By using the linear functions of performance or linear functions of heat rate on the power plant, can be made approach is an energy cost of the power plant. With a heating rate which is a linear function of the above, it was found that the fuel cost and emission cost is a quadratic function. The cost function of a power plant that supports an electricity system in Indonesia, which can be grouped into 3 main namely hydro power plant, thermal power plant, and geothermal power plant. In modeling the above, all the function approach quadratic with parameters such function parameters $\alpha, \beta$, and $y$ as shown in Equation.

The thermal power plant will generate greenhouse gas emissions for each power output, while hydro power plant does not emit greenhouse gas emissions. So that in addition to having function a thermal power plant fuel costs also have the cost of emissions, while the hydro power plant only has water retribution costs.

\subsection{Analysis of Simulation Model}

By using the quadratic model of a function of fuel costs and the cost of emission using the parameters as illustrated in Table 1, it can be seen that the parameter $y$ is negative. This can be attributed to the declining value of the power plant heat rate if the load to the nominal load.

Using dummy data from the power plant as shown in Table 3, are used to determine the parameters of the cost function of fuel and emissions costs as shown in Table 4. Differences objective function of fuel cost with emissions cost and fuel cost without the cost of emissions are shown in Table 4. From the Table 4, it is also shown that the parameter values in the objective function of fuel costs which included the cost of emissions will be of higher value than the parameter values without emissions costs included.

\subsection{Analysis of simulation results}

Having obtained the objective function of the function of fuel cost and the cost of emissions with constraints of its function. It can be done cost calculations namely their fuel cost and emissions cost or without emissions cost. Using data grid and load the data as shown in Table 5 and Table 6, and using interior point methods of calculation are used to determine the fuel cost with GHG emissions price as shown in Table 7. And then, calculated the cost of fuel without involving the cost of GHG emissions is shown in Table 8.

In situations of limited reserves of water, the hydro power plant can only serve the load at peak loads. Furthermore, based on Table 7 and Table 8 can also be seen, that the CPP is more likely to be the base load. Then for the load follower, tends to be done by gas-fired power plants, which is the CCPP and GTPP.

Using Table 9 can be shown that the costs related to the functioning of emissions, it will raise the overall operating variable costs of about $15 \%$ to $19 \%$. It is also related to the readiness of renewable energy power plants in servicing load, in this case, the HPP. The readiness of power plants with a low heat rate, it also will reduce emissions cost comparison to the cost of 
energy, shown in the drop in the percentage ratio of the value of emissions costs against the cost of energy on the hour to 3 to 5 hours.

\section{Conclusion}

The cost of GHG emissions can be combined with rising fuel costs as operating costs of electric energy generation by determining the parameters of every component of the cost of energy. By using the linear heat rate function model, it will be able to generate a single quadratic objective function both for fuel and emissions with function parameters $\alpha, \beta, y$ are dependent on other parameters as shown in Table 1. Based on the simulation result, GHG emissions cost can be reduced with more to generate of renewable energy i.e. hydro power plant as well as power plants with low heat rate.

\section{Acknowledgements}

The authors acknowledge Directorate General of Higher Education (DIRJEN-DIKTI) for giving financial support to this research via Doctorate Research Grant Scheme.

\begin{tabular}{|c|c|c|c|}
\hline \multicolumn{4}{|c|}{ Nomenclature } \\
\hline GPHR & Gross Plant (Heat Rate) & $H R_{H}$ & $\begin{array}{l}\text { Performance parameter of the hydro } \\
\text { power plant }\end{array}$ \\
\hline$H R_{\text {nom }}$ & Heat rate nominal & $\tau$ & Water density \\
\hline$H R_{\min }$ & Heat rate minimal & $g$ & The gravitational constant \\
\hline$P_{\text {nom }}$ & $\begin{array}{l}\text { Nominal power of unit power } \\
\text { plant }\end{array}$ & $h$ & Head of hydro power plant \\
\hline$P_{\min }$ & $\begin{array}{l}\text { Minimal power of unit power } \\
\text { plant }\end{array}$ & $Q_{\text {fuel }}$ & the rate of fuel consumption \\
\hline$P_{\text {aux }}$ & $\begin{array}{l}\text { Auxiliary power of unit power } \\
\text { plant }\end{array}$ & $N_{\text {fuel }}$ & Percentage of nitrogen content in fuels \\
\hline$P_{\text {aux }(\min )}$ & $\begin{array}{l}\text { Minimum auxiliary power of unit } \\
\text { power plant }\end{array}$ & $\varepsilon_{\mathrm{N}_{2} \mathrm{O}}$ & $\begin{array}{l}\text { Fraction of nitrogen oxidized to nitrous } \\
\text { oxides }\end{array}$ \\
\hline$C V_{\text {fuel }}$ & Calorific value of fuel & & The fraction of methane gas unburning \\
\hline$P$ & $\begin{array}{l}\text { Electric power generated by the } \\
\text { power plants }\end{array}$ & $P_{D i}$ & Active power of the load on bus $\mathrm{i}$ \\
\hline$P_{T}$ & $\begin{array}{l}\text { Total or gross power generated } \\
\text { by each unit of power plant }\end{array}$ & $P_{L i}$ & $\begin{array}{l}\text { Active power flow through the line from } \\
\text { bus i to bus } k\end{array}$ \\
\hline$\rho_{\text {fuel }}$ & The price of fuel & $P_{G i}$ & $\begin{array}{l}\text { Active power generated by the power } \\
\text { plant on bus } i\end{array}$ \\
\hline$\rho_{\text {em }}$ & The price of GHG emission & $\alpha, \beta, \gamma$ & $\begin{array}{l}\text { Parameters unit cost variable there are } \\
\text { depends on the type of power plant }\end{array}$ \\
\hline
\end{tabular}

\section{References}

[1] Kwang YL, Mohamed AES. Modern Heuristic Optimization Techniques Theory and Applications to Power Systems. John Wiley \& Sons: Hoboken, New Jersey. 2008.

[2] G Tzolakis, et al. Emissions' reduction of a coal-fired power plant via reduction of consumption through simulation and optimization of its mathematical model. Springer-Verlag. 2009.

[3] R Shum. Carbon's footprints: The politics of producing energy and emissions. ProQuest Dissertations and Theses. 2011.

[4] A Mangmeechai. Life cycle greenhouse gas emissions, consumptive water use and Levelized Costs of Unconventional Oil in North America. ProQuest Dissertations, and Theses. 2009.

[5] MA Rashidi. Improved optimal economic and environmental operations of power systems using particle swarm optimization. ProQuest Dissertations, and Theses. 2007.

[6] A Chatterjee, et al. Solution of combined economic and emission dispatch problems of power systems by an opposition-based harmony search algorithm. Electrical Power, and Energy Systems. 2012; 39: 9-20. 
[7] C Yassar, Ozyon S. Solution to scalarized environmental economic power dispatch problem by using a genetic algorithm. Electrical Power and Energy Systems. 2012; 38: 54-62.

[8] Ministry of Environment. Environment Minister of Republic Indonesia Number 349 of 2013 on Corporate Performance Rating on Environmental Management in 2012-2013. Jakarta. 2013.

[9] Soliman AH, Abdel AHM. Modern Optimization Techniques with Applications in Electric Power Systems. Springer: New York. 2012.

[10] J Zhu. Optimization of Power System Operation. John Wiley \& Sons: Hoboken, New Jersey. 2009.

[11] James K, Christopher JH. Effect of Cycle Parameters on Incremental Heat Rate. ASME, 86-JPCGPwr-75. http://heatrate.com/docs/Incremental-Heat-Rate-1985.pdf.1986.

[12] Joel BK. The Use of Heat Rates in Production Cost Modeling and Market Modeling. California Energy Commission. 1998.

[13] Richard C, et al. Estimating the Social Cost of Carbon Emissions. The Public Enquiry Unit HM Treasury Parliament Street, London. http://www.hm-treasury.gov.uk. 2002.

[14] RD Zimmerman, Murillo S. Matpower: User's Manual. http://www.pserc.cornell.edu/matpower/. 2011.

[15] T Nakata, M Sato, H Makino, T Ninomiya, Methods for predicting NOx emissions in coal combustion and unburned carbon in fly ash - Effects of coal properties, Criepi Report EW87003. Tokyo: Central Research Institute of Electric Power Industry, Yokosuka Research Laboratory. 1988.

[16] Jensen LS. NOx from cement production - reduction by primary measures. Ph.D. Thesis. Department of Chemical Engineering, Technical University of Denmark. 2000.

[17] Jensen LS, et al. Experimental investigation of NO from pulverized char combustion. Proc Combust Inst. 2000; 28: 2271-2278.

[18] JS Nordin, NW Merriam. NOx Emissions produced with combustion of Powder River Basin Coal in a Utility Boiler, U.S. Dep. of Energy. DE-FC21-93MC30127 Task 9. 1997.

[19] DW Pershing. Nitrogen-oxide formation in pulverized coal flames. The University of Arizona, ProQuest Dissertations and Theses. 1976: 411.

[20] PR Solomon, DG Hamblen, RM Carangelo, MA Serio, GV Deshpande. A General model of coal devolatilization. Energy Fuels. 1988; 2(4): 405-422.

[21] Masahide T, et al. NOx Emission Value - Study of Onboard Measurementuthors' Information. JIME. 2007; 42(6).

[22] Coal Industry Advisory Board. Power Generation from Coal, Measuring and Reporting Efficiency Performance and CO2 Emissions. International Energy Agency, 9 rue de la Fédération. 2010.

[23] James M, Tim M. The Unique Challenge of Controlling Biomass-Fired Boilers. http://www.powermag.com. 2010.

[24] JJM Berdowski, et al. Combustion In Energy and Transformation Industries. Emission Inventory Guidebook, TNO, P.O. Box 6011, 2600 JA Delft, The Netherlands. 1999.

[25] S Gil. Heterogeneous Destruction of Nitrous Oxide by Char. The Holistic Approach to Environment 2. 2012; $2:$ 51-60.

[26] Bo F, et al. Mechanisms of N2O Formation from Char Combustion. Energy Fuels, 1996; 10(1): 203208.

[27] S McAllister, et al. Fundamentals of Combustion Processes. Springer Science \& Business Media, LLC. 2011.

[28] R Weber. Combustion Fundamentals with Elements of Chemical Thermodynamics. ClausthalZellerfeld: Papierflieger. 2008.

[29] Zhou H, et al. Conversion of Fuel-N to N2O and NOx during Coal Combustion in Combustors of Different Scale. Chin. J. Chem. Eng. 2013; 21(9): 999-1006.

[30] XIE JJ, et al. Emissions of SO2, NO and N2O in a circulating fluidized bed combustor during co-firing coal and biomass. Journal of Environmental Sciences. 2007; 19: 109-116.

[31] The United States Tennessee Valley Authority. Heat Rate Improvement Guidelines for Indian Power Plants. Vol 1 Rev 1, USAID/India Greenhouse Gas Pollution Prevention Project (GEP). 2000.

[32] AB Gill. Power plant performance. Butterworth and Co (Publishers) Ltd. 1984.

[33] Public Utility Commission in SriLangka. Heat Rates of Thermal Power Plants in SriLangka. http://www.pucsl.gov.lk/english/wp-content/uploads/2014/03/REPORT-HEAT-RATE-TESTRESULTS.pdf. 2014.

\section{Biographies of Authors}

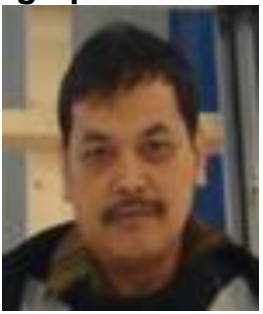

Ignatius Riyadi Mardiyanto is a lecturer in Energy Conversion Department, Politeknik Negeri Bandung (Polban), Indonesia. He was born in Klaten-Central Java, Indonesia, on January 12, 1967. He received S1's degree in Physics, from Bandung Institute of Technology, Indonesia in 1993 and S2's (Master's) degree in Instrumentation and Control Engineering, subject Asynchronous Generator Control from Bandung Institute of Technology, Indonesia in 1999. And now, he studies for Doctoral degree in Electrical Engineering -Sepuluh November Institute of Technology. 

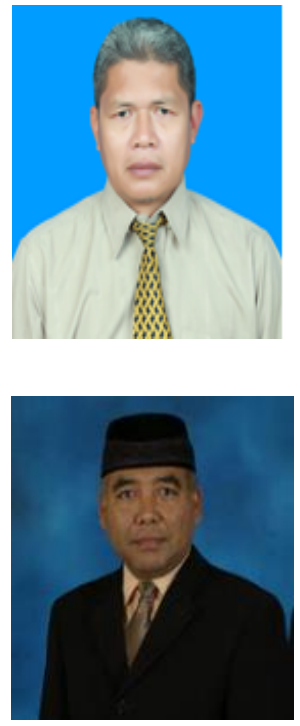

Hermagasantos Zein is a lecturer in Energy Conversion Department, Politeknik Negeri Bandung (Polban), Indonesia. He was born in Pasaman Barat, West Sumatra, Indonesia on July 11, 1959. He received S1's degree in Electrical Engineering with the subject Distribution Network, from Bandung Institute of Technology, Indonesia in 1985 and S2's (Master's) degree in Electrical Engineering with the subject Bad Data Identification in Electrical System from Bandung Institute of Technology, Indonesia in 1991. He obtained the Doctoral degree in Electrical System with the research subject Reduction Step in Interior Point for Optimal Power Flow from Bandung Institute of Technology, Indonesia in 2005.

Adi Soeprijanto is a lecturer at the Department of Electrical Engineering, Sepuluh November Institute of Technology (ITS-Surabaya), Indonesia. He was born in Lumajang-East Java, Indonesia, on April 5, 1964. He passed S1 degree on Electrical Engineering from Bandung Institute of Technology in 1988 and S2's (Master's) degree in Electrical Engineering from Bandung Institute of Technology, Indonesia 1995. He obtained the Doctoral degree in Power System Stability from Hiroshima University, Japan in 2001. 